\title{
CHILE EN LA EXPERIENCIA LATINOAMERICANA DE LA "SOLIDARIDAD" Y DEL NACIMIENTO DE LA "RAZÓN POÉTICA" EN MARÍA ZAMBRANO
}

\author{
CHILE IN THE LATIN AMERICAN EXPERIENCE OF \\ "SOLIDARITY" AND THE BIRTH OF "POETIC REASON" \\ IN MARÍA ZAMBRANO
}

\section{MADELINE CÁMARA*}

\section{RESUMEN}

El presente trabajo se propone contribuir a la genealogía de la razón poética, concepto clave dentro del pensamiento de la filósofa española María Zambrano y al respecto realiza un aporte esencial: el análisis detallado de un texto publicado en Chile que no había sido considerado en su importancia. Hablamos de "A los poetas chilenos de Madre España”, firmado por Zambrano en enero de 1937, texto-epílogo de la antología Madre España: Homenaje de los poetas chilenos.

Con el análisis de este texto se polemiza acerca de la idea aceptada en la bibliografía zambraniana de que el concepto razón poética emerge textualmente por primera vez en el artículo "La guerra de Antonio Machado", publicado en Hora de España XII, diciembre de 1937 (Zambrano, 1937d), cuando en realidad lo encontramos antes, escrito y publicado en el texto "Madre España". Mi objetivo no se dirige simplemente a probar que el concepto ha aparecido antes, sino a que ha nacido ya su expresión textual que, como se demostrará, funciona como una matriz por no decir aún como "un método".

Este debate no constituye un mero ejercicio de rigor académico, sino que aspira a enriquecer la visión que se tiene actualmente sobre la influencia de los contextos latinoamericanos en la obra de la pensadora española. Con el estudio de "Madre España" devolvemos este texto a su contexto histórico y a las circunstancias personales por las que atravesaba la autora cuando lo escribió. De esa forma, será más fácil proseguir analizando la espiral de desarrollo de su pensamiento y la compleja integración de géneros discursivos en su escritura.

Por último, se pretende destacar que la experiencia humana y colectiva de la solidaridad que constató en Chile debe ser considerada como una de las "categorías de la vida" que marcaron el inicio del itinerario de la razón poética en María Zambrano.

Palabras clave: Matriz, performance, razón poética, solidaridad.

\footnotetext{
* Professor of Latin American Literature, University of South Florida, USA. Correo electrónico: camaram@usf.edu
} 


\section{ABSTRACT}

This work contributes to the genealogy of the term "razón poética" [poetic reason], a key concept for understanding the thought of Spanish philosopher María Zambrano. In the process, it provides an essential contribution: a detailed analysis of the text published in Chile "A los poetas chilenos de Madre España", signed by Zambrano on January 1937 as an epilogue to the anthology Madre España: Homenaje de los poetas chilenos and whose importance had not been previously recognized. The analysis challenges the accepted idea found in the Zambranian bibliography as to the textual emergence of the concept "razón poética" [poetic reason] first taking place in the article "La guerra de Antonio Machado", published in Hora de España XII, December 1937 (Zambrano, 1937d). We actually find it before, written and published, in the text of "Madre España". The purpose of this work is not simply to prove the concept appeared before, but rather to indicate the birth of a textual expression and demonstrate its function as a matrix.

The debate does not constitute a mere exercise in academic rigor but rather seeks to enrich our view of what we currently understand to be the influence of the Latin American contexts in the work of this Spanish thinker. The study of "Madre España" allows us to return the text to its historical context and personal circumstances the author found herself in when writing. This will make it easier to continue to analyze the spiral development of María Zambrano's thought and complex integration of different discursive genres in her writing. Lastly, we point to the need to consider, as one of the "categorías de la vida" [life categories], the human and collective experience of the solidarity present in Chile at the time as one marking the beginning of María Zambrano's journey towards "razón poética" [poetic reason].

Keywords: Matriz, performance, poetic reason, solidarity.

Recibido: 11.08.12. Aceptado: 10.10.13.

\section{LA DÉCADA DEL 30: ESPAÑA - CHILE}

E N Los “eXistenciarios” de María Zambrano, como les llama Juan Fernando Ortega Muñoz (1982), la ruta latinoamericana fue la salida a la "Intemperie". Sin embargo, su primer contacto con el continente americano -la visita a Chile entre 1936 y 1937- podría situarse en las antípodas de sus posteriores estancias en México, entre 1939-1940 y en el Caribe hispano, Puerto Rico y Cuba, donde vivió y trabajó fluctuando entre las dos islas, incluido un viaje a Italia entre los años 1940-1953. Ya en estos países ella sería la filósofa exiliada, la discípula rebelde de Ortega y Gasset que se abría paso con una obra diferente a la de su maestro. Al llegar a Chile en 1936, también tenía estas credenciales, pero no creo que sean éstas las que la definan ni es ésta la imagen con que ella quiere presentarse al grupo de intelectuales que la acoge. Paso a explicarme y adelanto algunas hipótesis. 
Pienso que en Zambrano es determinante la consciencia de performance como mujer y escritora moderna. Siguiendo la línea de trabajo de la estudiosa norteamericana Vicky Unruh en Performing Women and Modern Literary Culture in Latin America (2006) hago una reapropiación de enfoque transatlántico del concepto de performance-que ella aplica entre otras a Teresa de la Parra y Victoria Ocampo, contemporáneas a Zambrano- y considero con Unruh que la performatividad de estas mujeres opera como una transformación de sus experiencias vitales y de escritura dentro de un mundo en que su agencia como intelectuales no era bienvenida. Sostiene Unruh que ellas utilizan esa performatividad tanto en su sentido teatral, cultural como discursivo, como un instrumento para poder llamar la atención y defender las particulares características de sus obras. La subjetividad de este tipo de autora moderna, entonces, puede verse como una tensión entre lo que muestran y lo que debe ser escondido, entre observar su entorno y ser observadas. Al reapropiarme del término, aclaro que no debe ser entendido en ningún momento como equivalente de simulación, lo cual implicaría un juicio ético contra quien lleva a cabo un performance, sino que siempre es visto aquí como una construcción cultural. En el caso particularísimo de Zambrano, como probaré en libro en proceso, dicho performance evolucionará hacia un fluido movimiento de máscaras -en la etimología griega del término-, encarnaciones de personajes.

Pero hablando solo del momento chileno, nos encontramos con una joven cuyo carisma impresiona por igual a hombres y a mujeres, que es reseñada por la prensa como "distinguida intelectual española" (citado en Soto, P., 2005) si bien era, por el momento, una desconocida en el resto de América Latina. No cabía duda de que había alcanzado cierto reconocimiento dentro de su país de origen por un libro publicado en 1930: Horizonte del liberalismo, así como por dos artículos: "Hacia un saber sobre el alma” " “'Por qué se escribe?”, ambos publicados en la prestigiosa Revista de Occidente en 1934; pero aún era una estudiante avanzada de doctorado que había desatendido su tesis sobre Spinoza para volcarse hacia un periodismo y un activismo político al servicio de la Segunda República Española. A esta realidad se ajusta perfectamente su triple performance: de activista -de ahí su asistencia a mítines y actos públicos en Santiago de Chile-; de esposa de un diplomático -por eso su declarada reticencia a publicar sus opiniones políticas en la prensa del país- y de "apasionada" escritora antifascista -lo cual demuestra con la productividad de sus textos concebidos, editados y publicados en la corta estancia chilena-.

A lo más sur de América Latina llegó el 18 de noviembre de 1936 esta 
joven que en verdad no difería en mucho de otras mujeres intelectuales españolas de su época en España, donde nombres como Maruja Mallo y Rosa Chacel se pueden citar entre la vanguardia del arte de la península, ambas amigas cercanas de Zambrano (Johnson, 2003). Tenía sólo 28 años y llegaba del brazo de un apuesto esposo recién nombrado diplomático en este país por el gobierno republicano, el historiador Alfonso Rodríguez Aldave, quien también trabajaba incansablemente junto a Zambrano en organizaciones políticas y estudiantiles españolas, al lado de la amenazada democracia. Ambos eran miembros de la "Alianza de Intelectuales para la Defensa de la Cultura" (AIDC) que fue la respuesta española a la celebración del "I Congreso Internacional de Escritores en Defensa de la Cultura" en París, en 1935.

Las actividades que ya había desarrollado en España "la joven pareja española" -como se les ha llamado- hizo que fueran abordados por la intelectualidad de izquierdas chilena que vería en ellos a embajadores, no por decreto, sino por excelencia, de los escritores españoles que ejemplarmente representaban el concepto de compromiso político (Soto, H., 1996; Valender, 2010). De lo comentado por estos estudiosos, deducimos que Zambrano se movió entre escritores de orientación ideológica de izquierdas: la llamada "Alianza de Intelectuales", fundada en 1937 en acto encabezado por Pablo Neruda; el "Frente Popular", creado en 1937 para llevar a la candidatura a un Presidente de ideas antifascistas, Pedro Aguirre Cerda; la $\mathrm{MEMCH}$, grupo femenino de proemancipación de la mujer chilena y, finalmente, los movimientos populares liderados por la Central Única del Proletariado Chileno, en una de cuyas marchas en Santiago cuenta Zambrano haber oído de obreros chilenos la expresión "Madre España". Sin embargo, no creo sea coincidencia que uno de los mártires de la guerra civil española, el poeta campesino Miguel Hernández, amigo personal de Zambrano, usara también esa expresión como título de unos de sus poemas, "Madre España".

Los pormenores de las actividades tanto políticas como literarias que ambos realizaron en Chile, incluso su llegada misma, ya están estudiados en los artículos de Pamela Soto. En su artículo de 2005, ella establece otra sugerente conexión no directamente política entre las vivencias de esa etapa y los temas de lo femenino y lo maternal, tópicos que de modo más profundo y conceptual exploran Roberta Johnson (2003) y Elena Laurenzi (1995), entre otras estudiosas zambranistas. 


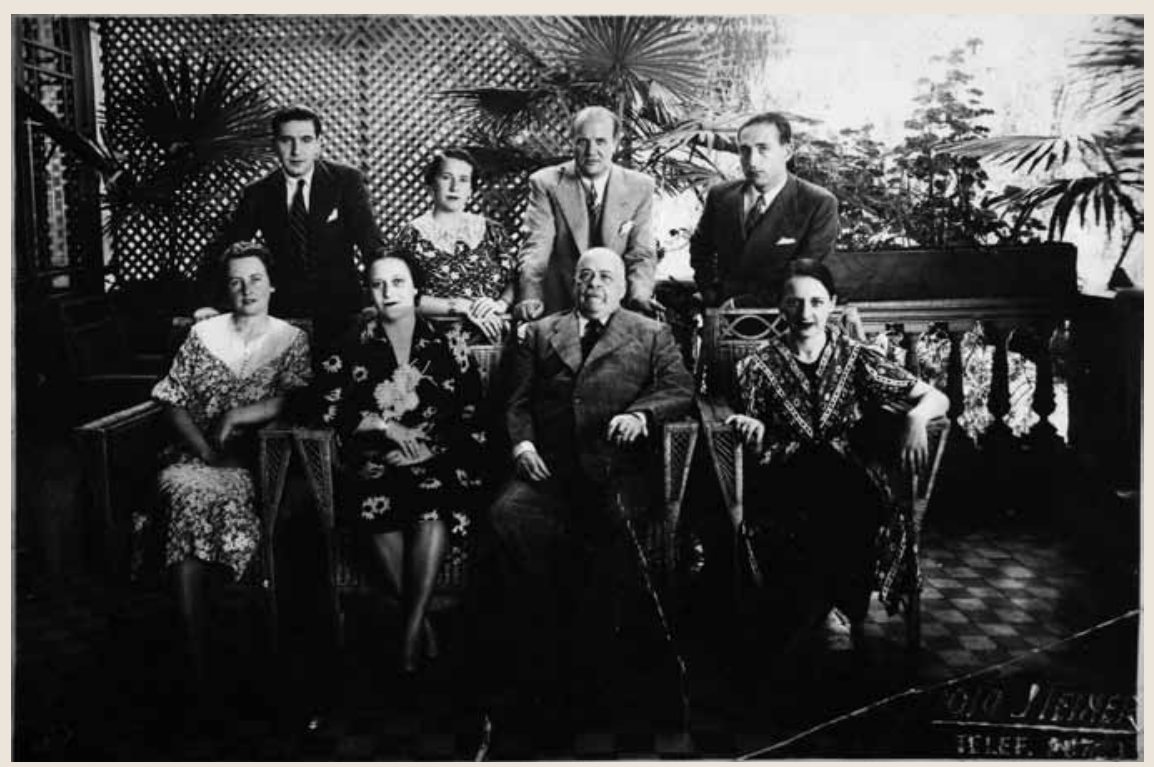

En Santiago de Chile, María Zambrano, sentada a la derecha. Su esposo, Alfonso Rodríguez Aldave, de pie a la izquierda.

Será Pamela Soto quien nos informe de la publicación casi inmediata a su llegada a Chile, del artículo periodístico "La mujer en la lucha española” (citado en Soto, P., 2005) en el que Zambrano sigue la línea de expresa defensa de los derechos de la mujer y de los valores de la figura de la madre en períodos de guerra, algo que venía haciendo ya en España desde su columna “Mujeres" en el periódico El Liberal, tan temprano como en 1928 (Ortega, 2007). Téngase en cuenta este aspecto en vinculación con el uso de la metáfora de Madre España que despliega como bandera de convocación, en el texto que luego estudiaremos.

\section{LA RAZÓN POÉTICA EN “MADRE ESPAÑA”}

Dada su escasa divulgación, creo que vale la pena transcribir para el lector el texto completo de Zambrano que será analizado en el presente trabajo. Copio directamente del facsímil del original reproducido en el portal de la cultura chilena www.memoriachilena.cl, pues así puedo ofrecer la pagina- 
ción original que se pierde cuando el texto se incluye en la Antología de la solidaridad chilena: España 1936, preparada por Hernán Soto. Sin embargo, advierto que hay un error en el año que figura en la ficha bibliográfica que el portal ofrece para el facsímil de la antología, mientras que Hernán Soto sí lo ofrece correctamente. No hay duda de que la publicación es de 1937 ya que el texto de Zambrano, como puede observarse en el propio facsímil, está firmado en enero de ese año y también, en este mes y año, firma Gerardo Seguel su introducción a dicha antología.

\section{"A LOS POETAS CHILENOS DE 'MADRE ESPAÑA"}

ES EN LA HONDA profundidad del silencio, allí donde aguardan las palabras todavía por nacer, donde España, la verdadera e indivisible, va a recoger, hermanos poetas de Chile, vuestra voz desgarrada.

En el ancho seno de madre, profundo seno maternal, serán recibidas vuestras palabras de verdadera poesía y serán recordadas siempre con la memoria permanente de la historia real, de ésa que constituirá el alimento y la nutrición del hombre nuevo que surge entre la sangre.

En esta terrible conmoción de España se comprueba su condición de madre. Todas las notas de la maternidad esenciales se encuentran en ella exaltadas hasta el máximum: dolor sin límite, fecundidad y esa mezcla de lo divino con lo carnal y sangriento, ese palpitar de lo infinito por venir entre entrañas desgarradas; esa agonía de vida en que la muerte queda vencida como un toro arrodillado.

Todos los hombres cuyo corazón está abierto al futuro se sienten hoy hijos de España y todavía más de entre ellos los que vierten sus pensamientos en el claro idioma que ella les enseñó como madre. Madre del "nuevo mundo" siempre España. Os sentís ahora alumbrados por ella, renacidos, transformados en descubridores de la nueva época histórica que hemos de cuajar entre todos.

Y para que nazca esa nueva época, ese mundo justo, luminoso e infinitamente humano, se quiebra hoy su tierra amarilla, se queman sus finos olivos bajo la metralla, se trastorna su luz y su cielo y vienen abajo las altas torres puestas en pie por voluntades de siglos. Campos de tragedia sus encinares y roquedas, sus empinadas sierras y sus pálidas llanuras. Llorad, sí, poetas hermanos sobre su tierra humeante de pólvora, caliente de sangre y helada de cadáveres; llorad por todo eso que desaparece -belleza única e irreconstructible- ametrallado, herido, derrumbado y pisoteado por cascos de caballos africanos y por ciego odio sin entrañas.

Una iniquidad sin nombre se ha conjurado sobre nuestra madre España para aniquilar su fecunda maternidad y sustraer al mundo su fruto. No podrán lograrlo porque la realidad histórica tiene algo de invulnerable como la vida misma y el pueblo español que encarna hoy el 
punto más alto -más real- de la historia sabe no retroceder. Lo ha probado repetidas veces, con sus apariciones discontinuas y esplendentes como relámpago que atraviesan el horizonte del mundo. Por extraño que parezca, la verdad es que España es una promesa, algo en lo que pesa más la tarea por hacer, que su largo pasado ya hecho y esta verdad hasta ahora sabida por unos pocos, es ahora evidente para todos los que son capaces de entender. Con sus piedras de siglos, sus tradiciones de la más remota antigüedad, España no era nunca arqueología sino vida en potencia y su pueblo la más grande reserva moral del mundo moderno. Por eso era obligado que todos los poderes reaccionarios, que todas las fuerzas agónicas, último desecho de un pasado que ya no tiene vigencia, hayan atentado contra este pueblo lleno de futuro. No se equivocaron de blanco; el pueblo español con sus infinitas reservas morales y sentimentales, humanas, con sus tres siglos por lo menos de barbecho constituye hoy en el viejo mundo, el germen poderoso, el renacimiento de un mundo nuevo.

Y es con la poesía y con la palabra, es con la razón creadora y con la inteligencia activa en conjunción con esa sangre que corre a torrentes, como hay que forjar este Renacimiento del pueblo español que traerá un mundo nuevo para todos los pueblos. Brota la fecundidad de esta conjunción de dolor humano y razón activa, de la carne que sufre y la inteligencia que descubre. Sólo el dolor no bastaría porque la pasividad nunca es suficiente, ni tan siquiera la fiera lucha armada; es preciso y más que nunca el ejercicio de la razón y de la razón poética que encuentra en instantáneo descubrimiento lo que la inteligencia desgrana paso a paso en sus elementos. Es necesaria y más que nunca la poesía y por eso es que brota entre vosotros, hermanos chilenos que contribuís así a la lucha de España acompañándola, dándole vuestra voz de amor y de esperanza, de afirmación filial en instantes en que sus entrañas maternales sufren la agonía de la vida creadora.

\section{MARÍA ZAMBRANO}

Santiago de Chile, Enero de 1937 (pp. 38-39)

Para analizar este breve, pero enjundioso texto, vuelven a serme útiles las teorías del filósofo de la lengua de origen norteamericano, John Austin, sobre el "acto de habla" -aquellos actos que realizamos con palabras- que desde hace tiempo utilizo para analizar la escritura de ciertas mujeres intelectuales que combinan la inclinación poética con la política (Cámara, 2001); en particular, el original análisis de lo que Austin llama "expresiones realizativas" (performative utterances) y la noción de fuerza locutoria. Este 
autor acuña el término locución para referirse a la realización de un acto al decir algo, por ejemplo, "preguntando o respondiendo una pregunta, dando alguna información, o dando seguridad, o formulando una advertencia, anunciando un veredicto o propósito, dictando sentencia, concertando una entrevista o haciendo una exhortación o crítica, haciendo una identificación o una descripción y muchos semejantes" (Austin, 1996, p. 143); en contraste con el término perlocución, que él propone usar cuando "producimos o logramos algo porque decimos algo, tales como convencer, disuadir e incluso digamos sorprender o confundir" (p. 152). Resumiendo, para conveniencia de este artículo, en su compleja teoría podría decirse que la locución la realiza el hablante mientras que la perlocución es realizada por el oyente. Con estas precisiones en mente, designamos en el texto "Madre España" a su autora, María Zambrano, como el hablante, y a los poetas chilenos, como sus oyentes.

Zambrano abre el escrito con una fuerte estrategia retórica: la creación de un vacío, "la honda profundidad del silencio", donde podrá oírse "vuestra voz desgarrada", la de los "hermanos poetas de Chile" que, como apreciará el lector, es una expresión en posición vocativa. Se establece de inmediato un escenario casi teatral y simbólico, pues dichas palabras serán recibidas en "el ancho seno de madre", connotación que pasa a tener España en el texto. Diríase hasta aquí que la función locutiva de estas primeras oraciones es ésta: transmitir seguridad al interlocutor sobre la capacidad maternal de España respecto a sus hijos chilenos, y de la legitimidad de Zambrano para llamar "hermanos" a los poetas, como ella, escritores.

El segundo párrafo recoge una pluralidad de "motivos" en el sentido semántico que da a este término el formalista Boris Tomashevsky (1965). Primero, el de "la verdadera poesía", que deberá entenderse por contraposición no explícita con aquélla que hacen los "señoritos", en lo que resuena el eco de Blas Zambrano y de Antonio Machado en María Zambrano; segundo, el concepto de "historia real", de gran significación para las teorías metafísicas que más tarde ella elaborará en contraposición con las ideas positivistas sobre la Historia; tercero, el emblema "del hombre nuevo", que veremos resurgir a lo largo de su obra como "Hombre Verdadero"; y cuarto, la presencia ineluctable de "la sangre", que se nos muestra real, carnal, pero que luego devendrá, en el lenguaje zambraniano, en una suerte de "archipalabra".

En el tercer párrafo, sigue desarrollando la retórica de reforzar la imagen de España como madre y de la maternidad misma, aparece la palabra "entrañas" que también actúa como un "motivo" en el pensamiento zambraniano posterior. Enlazadas con estas oraciones, entra en el párrafo siguiente 
la exposición del tópico idioma compartido: el español "que ella [España $\mathrm{MC}]$ les enseñó como madre". Ejerce de nuevo Zambrano la presión desde el vocativo, lográndose una clara expresión perlocutiva, pues aspira a transformar a sus oyentes: "Os sentís ahora alumbrados por ella, renacidos, transformados en descubridores de la nueva época histórica que hemos de cuajar entre todos."

El párrafo quinto pasa a la estrategia de la descripción de España como espacio físico del "sacrificio": "tierra amarilla", cuyos "finos olivos" se queman bajo "la metralla" que trastorna "su luz y su cielo" y derrumba "las altas torres puestas en pie por voluntades de siglo", demostrando la finísima capacidad paisajista de Zambrano, que pinta para punzar los sentidos y aguzar la relación afectiva entre los hijos y la madre sufriente. Por ello, porque se experimenta una tragedia, se impele a los chilenos nuevamente mediante una expresión perlocutiva: "Llorad, sí, poetas hermanos sobre su tierra humeante de pólvora, caliente de sangre y helada de cadáveres".

Dado que el espacio con que cuenta la autora es poco, una vez aseguradas las funciones vocativas, locutivas y perlocutivas del texto, Zambrano se extiende en un argumento que la apasionaba: España como "promesa", dado que posee "su pueblo las más grande reserva moral del mundo moderno". Pasemos al párrafo conclusivo donde Zambrano dispone de trece líneas para desarrollar temas de gran importancia dentro de su pensamiento político y filosófico.

La oración que abre este párrafo comienza con la conjunción "Y" que luego se convertirá en un muy utilizado recurso estilístico que marcará la prosa de Zambrano, apareciendo a menudo en la apertura de sus párrafos. Como sabemos, la función gramatical de esta conjunción copulativa puede ser la de acumular términos, oraciones o unidades sintácticas, o actuar como conector entre las mismas; puede indicar también adición, crear la idea de unidad entre dos o más términos homogéneos, crear la impresión de repetición indefinida e incluso dar énfasis a una frase o pregunta. Creo que todas ellas son empleadas por Zambrano, pero demostrarlo conllevaría otro tipo de análisis. En el texto que nos ocupa, veo esta partícula gramatical como un elemento de énfasis para llamar la atención del lector sobre ese párrafo de cierre y sobre todo como cópula entre la nueva idea que se pasa a desarrollar y todos los argumentos posteriores.

Es por ello posible que encontremos que en este párrafo germina, semánticamente, la razón poética. Estalla como una matriz, un centro de irradiación de sentido, en la acepción que Michael Riffaterre atribuye a ese término dentro de la poesía: "El poema resulta de la transformación de una 
matriz, una mínima frase literal, en una más compleja y no literal perífrasis. La matriz es hipotética, siendo solo la actualización gramatical de una estructura" (Riffaterre, 1978, p. 19, mi traducción). Como hablamos de la prosa poética zambraniana, me parece posible pedir en préstamo el término "matriz". Aquí será una espiral de propuestas de lecturas que se suman espaciadamente en el texto con la ayuda de la conjunción "Y": "poesía, palabra, razón creadora e inteligencia activa". Cuando todos estos elementos de profunda connotación simbólica se conjugan con "la sangre", entonces la voz autoral vuelve a imponerse con una fuerte locución, un mandato dicho desde la Fe: "hay que forjar este Renacimiento del pueblo español que traerá un mundo nuevo para todos los pueblos". A continuación seguirá argumentando, con un lenguaje altamente inflamado, "que es preciso y más que nunca el ejercicio de la razón y de la razón poética que encuentra en instantáneo descubrimiento lo que la inteligencia desgrana en sus elementos".

Pienso que en esta primera manifestación textual de la razón poética están muy claros los principales ingredientes que la han conformado: las huellas del pensar de sus "mayores" y de sus hermanos de generación que ella ha incorporado creativamente; el peso de las experiencias personales por las que está atravesando como esposa de un diplomático de la República en armas en la América española, y su compromiso político como intelectual en aunar esfuerzos para la lucha antifascista en España y a nivel mundial. Todo esto se une a la urgencia de manifestar sus indudables inclinaciones de escritora, forjando un estilo literario que ya va perfilándose como muy personal, capaz de sintetizar el carácter comunicativo y movilizador de un texto con la presencia de conceptos que resultarán cardinales en su etapa de madurez filosófica.

Creo que José Ortega y Gasset y su "razón vital" son los ecos presentes cuando Zambrano subraya la capacidad "creadora" de la razón -que ella llama "razón activa"- y que actuará fecundamente solo si se conjuga con la "carne que sufre" y "la inteligencia que descubre". ¿Podríamos en esta última frase recepcionar el concepto de "inteligencia sintiente" de Xavier Zubiri, quizás absorbido en las clases que tomó con él? O incluso entrever la influencia de Manuel García Morente -el profesor que no le dio la mejor nota- cuando Zambrano enfatiza en la importancia de la "intuición", al hablar de ese "instantáneo descubrimiento" que puede hacer la razón poética opuesta al analítico operar de la inteligencia que "desgrana".

Pero dejo a los especialistas en filosofía zambraniana la tarea de analizar todas las influencias de "los maestros" que pueden alimentar la concepción de la famosa frase que luego definirá la originalidad de la discípula. A mi 
juicio, estamos ante toda una propuesta in nuce del saber zambraniano, que concibo como un palimpsesto, un tejido que opera sobre los hilos de su circunstancia histórica y personal, así como sobre las voces cercanas o lejanas que ella identifica como transmisoras del pensar humano de todos los tiempos. Aprehensión poética, síntesis plutónica, fragmentación discursiva, todo mezclado.

Una vez dicho aquello que a Zambrano le urge expresar como escritora y como pensadora, habiéndose fraguado en esta prosa de circunstancia su tan influyente definición operante de razón poética, queda a la activista política la responsabilidad de cerrar su escrito con un llamado inequívoco a sus interlocutores:

Es necesaria y más que nunca la poesía y por eso es que brota entre vosotros, hermanos chilenos que contribuís así a la lucha de España acompañándola, dándole vuestra voz de amor y de esperanza, de afirmación filial en instantes en que sus entrañas maternales sufren la agonía de la vida creadora.

Me he tomado la libertad de subrayar las palabras escogidas por Zambrano para apreciar mejor el artificio con que vuelve sobre términos claves, con los que compromete al pueblo chileno $-\mathrm{y}$ en particular a sus poetas, sus intelectuales- al ejercicio de una solidaridad práctica, la que de hecho se manifestó día a día en las calles chilenas en los mítines a favor de la República; la que más tarde se corroboró con la llegada masiva a Chile de exiliados españoles a bordo del "Winnipeg" en 1939, y la que practicaron sus escritores y su Presidente Aguirre Cerda en los momentos de la lucha antifascista. Seguirá ella pidiendo el ejercicio de solidaridad cuando regrese junto a sus hermanos españoles, para que dejen de despedazarse entre facciones y despedazar a la Patria; solidaridad que, terminadas las guerras, sigue apareciendo en el ideario zambraniano -ya para entonces mucho menos politizado- en términos de hondo sentido cristiano, tales como "Piedad" y "Compasión".

\section{LA RAZÓN POÉTICA: HACIA UNA REFORMA DEL PENSAR QUE INCLUYA EL ALMA}

Pasemos ahora a revisar el texto que prosigue en fecha de publicación dentro del período chileno: "La reforma del entendimiento" (1937b). Tal y como sugiere su título, se trata del trabajo más ambicioso de Zambrano 
-y lo es además en número de páginas y estructura- que adopta la forma típica del artículo periodístico zambraniano, en realidad, ensayo en prosa poética. No obstante, podemos notar la continuidad de este texto con el de "Madre España" en la historicidad que ambos rezuman, la inmersión de la letra en la vida. Clama Zambrano sobre "la necesidad... de la penetración de la razón en esas zonas insondables de lo irracional. Necesidad que no brota de una ambición de conocer, de una soberbia del entendimiento sino, muy al contrario, de circunstancias pavorosas por las que pasa el hombre" (Zambrano, 1937b, p. 122), en referencia obvia a la guerra civil española y a la amenaza del Fascismo para Europa y para el mundo en general.

Pero sigamos el rumbo de la razón poética que reaparece en estas líneas al hablar de los posibles caminos para realizar esa reforma crítica tan urgente para el entendimiento. Al respecto, coincido con Bungard (2009, p. 260) cuando considera este texto de Atenea como una exposición "programática" de la razón poética.

Véase como Zambrano acepta que aunque ya los estudiosos han intentado "volverse hacia el instrumento mismo, analizar su estructura" (Zambrano, 1937b, p. 116), es decir, hacer la crítica a la "falibilidad del instrumento intelectual" (p. 115), es preciso cultivar un camino alternativo: "Este segundo modo de hacer la crítica del entendimiento incluiría, para ser completa, una conciencia de todo aquello que no entra bajo la luz del entendimiento, o al menos de su existencia. Es la cuestión de la razón y de lo irracional que se cruza con la del ser y el no ser" (p. 116). Sin duda, estamos de nuevo ante otro reclamo como aquel que hizo Zambrano a la filosofía en "Hacia un saber sobre el alma" (1934), el artículo que le costó la reprobación de Ortega y Gasset. Allí pidió espacio para el alma dentro de la cuestión de la razón y seguirá haciéndolo en su texto de 1937, todavía en diálogo con el maestro. La cito: "Ortega y Gasset en su ensayo del año 1924 'Ni vitalismo ni racionalismo', analizando la teoría de la razón expuesta al modo clásico por Leibniz, dice: 'La razón es una breve zona de claridad analítica que se abre entre dos estratos insondables de irracionalidad' (...). Y éste podría ser el resumen de la crítica de la razón hecha desde el punto de vista de su puro funcionamiento" (1937b, p. 121). Sin embargo, no niega Zambrano que "... del largo pasado racionalista nos ha quedado prueba de que la razón ha podido alcanzar resultados positivos" (p. 123). Esta afirmación viene precedida de un examen de los períodos históricos en que se ha intentado la reforma de la razón, pasando desde su triunfo en la época clásica grecorromana, hasta su primera crisis en el Renacimiento y luego, a partir de la crítica kantiana y las sucesivas críticas, tanto filosóficas como 
poéticas, que se hacen al racionalismo desde el Romanticismo. Su enfoque es más epistémico que historicista, algo típico en Zambrano, pero es la base que le permite lanzar su propuesta: "Se trataría, por tanto, de descubrir un nuevo uso de la razón, más complejo y delicado, que llevará en sí mismo su crítica constante, que tendría que ir acompañado de la conciencia de la relatividad” (p. 123). ¿Será entonces un ensanchamiento de la franja demarcada a la razón por Ortega lo que pide su contestataria discípula?, ¿una porosidad tal que le permita conectarse con los espacios de irracionalidad?

Considero extraordinaria la flexibilidad del pensamiento zambranista para dialogar con los logros del pensar que le preceden sobre el tema de la racionalidad y subrayo la vigencia de las propuestas a las que llega, válidas incluso hasta nuestros días, cuando pide a la razón "asimilarse a la historia" (p. 123). Lo que antes ha llamado ya razón poética, en el presente texto resurge como zona de movimiento y contacto, pues la razón ha de "adquirir una estructura dinámica en sustitución de la estructura estática que ha mantenido hasta ahora" (pp. 123-124). Ese espacio es el mismo, a mi entender, que se concretará en la metáfora del claro del bosque, con la que Zambrano entrará en contrapunteo con el pensamiento de Martin Heidegger. La frase se convierte en título para uno de los libros de madurez de Zambrano: Claros del bosque (1977), concebido en su exilio definitivo, que será considerado por la crítica como uno de los máximos exponentes de la razón poética. Con él se traza un arco entre: la discusión en las aulas de Madrid, las reflexiones que le mereció la lectura de El ser y el tiempo, y sus propias experiencias vitales, ya al final de su vida, cuando convive sola con su hermana enferma en una finca enterrada en el Jura francés. Coincido con Moreno Sanz (1993, pp. 65-66) en que Zambrano no prolonga en su libro el discurso del maestro alemán, sino que "lo hiere en su mismo centro" (p. 65). La discípula de aula y de lecturas se esfuerza siempre por reinscribir su Palabra en la ya dicha por los grandes maestros, pero socavando, removiendo y aireando la raíz de lo discutido, práctica en la que la siento discursivamente próxima al deconstructivismo de Jacques Derrida. Pero no habría que apresurarse en presentar a Zambrano como antecesora del Posmodernismo, pues ella no se regodea en el constante deslizamiento de los significantes, sino que aspira a hacer aflorar la Palabra, sirviendo ella como "Guía". Deberá entonces quedar asido en el palimpsesto de su escritura, un significado, un sustrato más que lingüístico, conceptual -si bien en un amplio sentido- para que la Palabra cumpla su función, que será ético-religiosa en la Zambrano de madurez. Esa tendencia, esa vocación, se indica desde este temprano escrito de Atenea, cuando leemos: "es menester 
una nueva y decisiva reforma del entendimiento humano o de la razón que ponga a la razón a la altura histórica de los tiempos y al hombre en situación de entenderse a sí mismo" (Zambrano, 1937b, p. 80).

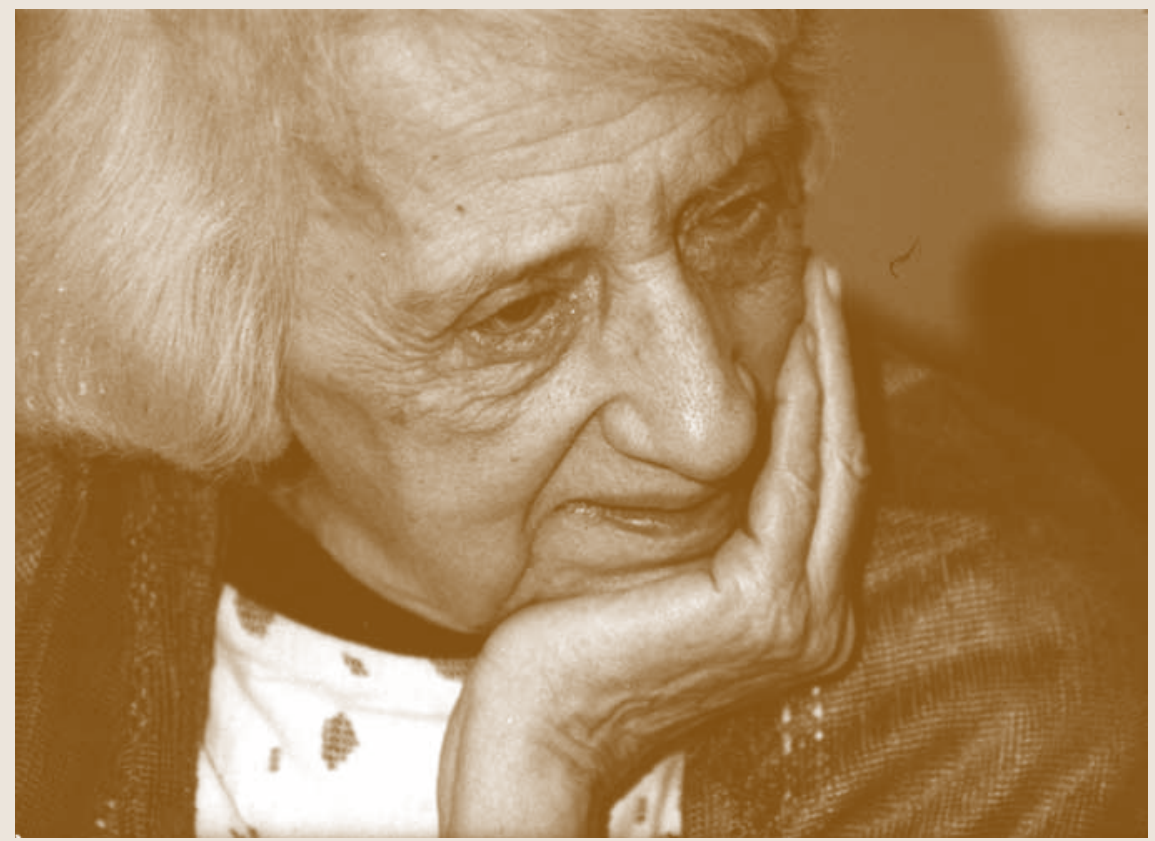

María Zambrano, a fines de los años 80.

\section{CONCLUSIONES DESDE “iLA AMÉRICA MATERNAL: TAN ANCHA!"}

Solo hubo dos regresos a España para María Zambrano; aquél del 19 de junio de 1937, cuando abandonó Chile junto a su esposo para incorporarse a las filas del Ejército Republicano, precisamente porque la guerra estaba perdida, como dijera ella en su momento; y el regreso definitivo de 1984, de su largo exilio de más de 40 años, cuando fue recibida con honores en una España postfranquista, pero que ya ella no pudo concebir como su Patria. Amaba demasiado su exilio, dijo también. El primer regreso lo narró en un elocuente artículo: "Españoles fuera de España” (Zambrano, 1937c), publi- 
cado en Hora de España, escrito quizás durante el viaje mismo que efectuó por barco; el último regreso, puede decirse que fue escrito varias veces con antelación al evento mismo, en las múltiples cartas que envió a sus amigos cercanos y en entrevistas que concedió a la radio, en las que Zambrano envió a España, primero su Voz, como adalid de su cuerpo. La llegada terminó por ocurrir en el aeropuerto de Madrid un 20 de noviembre y también fue descrita varias veces por la prensa del momento y rememorada por la propia Zambrano en escritos semibiográficos posteriores. Se desplegó entonces el escenario final de su performance: María, la sibila, que recibía a una nueva generación de escritores devotos de su obra, en el pisito de Madrid, en la calle Antonio Maura 14, cuya atmósfera intenta reproducir la película española María querida, del año 2004, dirigida por José Luis García Sánchez. Es en esa "definitiva tranquilidad en "lo paralelo e indispensable en el vivir" (citado en Moreno Sanz, 1993, p. 627) donde seguirá cultivando su nuevo ordo amoris -la razón poética- rodeada de nuevas y viejas compañías.

Muchos de estos admiradores y admiradoras de Zambrano provenimos del "Nuevo Mundo", la América que nos ayudó a refundar, repensándola desde nuevas categorías. Por eso, como académica cubana radicada en los Estados Unidos, conocedora de las intemperies y los exilios, he querido contribuir al estudio de su valiosa obra.

En este trabajo se sostiene que no podemos negar la raíz histórica del pensamiento zambraniano -inscrito en su momento, su realidad y sus vivencias- pero que a la vez sería absurdo no reconocer que ella aspiraba a que su escritura pudiese encarnar y revivir otras épocas y otros sujetos, en lo que yo prefiero llamar una vocación transhistórica, que atraviesa la historia sin ignorarla y que arrastra también consigo los sueños de los individuos. La autora misma utiliza el sustantivo "transhistórico" con una acepción similar, precisamente hablando de César Vallejo y de la historia de la conquista española de América, en su artículo "Hora de España XXIII", que recopila Moreno Sanz en su edición de 1998 (p. 289).

María Zambrano, la filósofa mística que fue al final de su vida, estaba convencida de que la "Palabra" enunciada por ella fue "recibida" y debía ser transmitida. Como investigadora, me he propuesto la tarea metodológica de examinar esa idea zambraniana desde un contexto diferente al religioso que le dio origen, pero sin ignorarlo. He estado tentada por la aventura intelectual de acercarla a los enunciados de la filosofía llamada posmoderna, pero no estoy convencida; estos caminos no prometen "salvación" alguna para el hombre y de esa utopía no podría yo privar al pensamiento zambraniano. No obstante, resulta obvia la posible analogía entre algunas frases de 
Zambrano sobre la Palabra y la concepción de la misma en el pensamiento de uno de los representantes del posmodernismo, Jacques Derrida, en particular en su texto "La palabra robada (soplada)" (1989) -que no citaré pues sólo quiero sugerir un interesante "sendero" de reflexión-. Sea o no el lugar a donde llegaría el conocimiento que quiso transmitirnos Zambrano, lo cierto es que esa "palabra zambraniana", que deviene sucesiva y/o simultáneamente en sus escritos: Razón poética, Logos y Espíritu, tuvo que horadar los cánones de la tradicional Filosofía de su época y su anterior legado, para solo entonces poder "instrumentarse" a través de ella como autora (aunque recordemos que se llamaba a sí misma "Autor").

Es lógico inferir que esta convicción tan profunda, este sentido de "llamado", no partía únicamente de su genuino pero muy particular catolicismo, de su $f e$, sino también hubo de engendrarse desde etapas tempranas en su pensamiento y su acción política. Por ello, fue temprana el alba de la razón poética.

¿Cómo podríamos unir en nuestro análisis categorías de tipo histórico -como son la consideración de las alianzas ideológicas hechas por Zambrano en España y en Chile o su propia praxis en el terreno de las agrupaciones partidistas y políticas- con concepciones que emanan de una visión del mundo religiosa, como la de "Orbe", propuesta por Agustín Andreu (2002), uno de los más agudos lectores de Zambrano? Parecería imposible, pero tratándose del estudio de la obra de esta pensadora debe intentarse esta reconciliación de modos de ver el mundo. Por ello, al cerrar por el momento estas lecturas, estoy más cerca de los juicios de la historicidad que le atribuye Valente (citado en Ortega, 1982), que de la apreciación de Bungard (2009) sobre el antihistoricismo de Zambrano, en la medida en que la práctica escritural de nuestra filósofa busca situarse en esos planos "transhistóricos", no simplemente históricos o antihistóricos.

Cito de la propia Zambrano las palabras con que cierra un texto clave para entender su posición sobre este tema; se trata del prólogo de su libro Senderos, publicado en 1986, y titulado "La experiencia de la Historia (después de entonces)". Nótese que se escribe cuarenta años después de 1937, cuando publicó Los intelectuales en el drama de España, en Chile. Sugiero entonces que este prólogo se lea como un poderoso metatexto de su pensar, sobre el tema de la participación del intelectual en la Historia, a la distancia de cuatro décadas. Leamos:

Cada generación que despierta se siente protagonista de la Historia. Mas habría que hacer una observación. Y es que el momento histórico consume varias generaciones, entre las que se incluyen las que padecieron 
bajo el poder de lo apócrifo y de su innumerable y cruenta persecución. Y las que despiertan ya en lo que parece ser el dintel de la historia verdadera, se sienten llamadas, como es este caso, a recoger el momento histórico que no acaba de entrar en el pasado; a hacerse vaso de su trascender, y a mirarse ellos en este ahora, en ese espejo que les ofrece el rostro y la figura incompleta y temblorosa, como un alba, del hombre verdadero. Ese ser que despierta en la inocencia en medio de la historia, que sin él no sería nunca universal, ni tan siquiera visible (Zambrano, 1986, p. 24).

La obra de esta intelectual transgresora y única fue definida por Agustín Andreu con palabras que invitan a seguir explorándolas: "Lo que he de decir es que la inmersión de María en la experiencia de la vida como sensación de destinación en lo divino, es ya 'locus theologicus' de importancia imprevisible, cuyo verdadero valor señalarán las generaciones futuras" (Andreu, 2002, p. 369).

En estas páginas, he tratado de entenderlo como un lugar de enunciación y también como el performance de una mujer extraordinaria. La lec-

tura desde la religiosidad y el análisis desde la retórica no tienen por qué contraponerse para llegar a María Zambrano.

\section{REFERENCIAS}

Andreu, A. (2002). Cartas de la Pièce. Valencia, España: Pre-Textos.

Austin, J. L. (1996). Cómo hacer cosas con palabras: palabras y acciones. Barcelona, España: Ediciones Paidós (How to do things with words, Cambridge, MA: Harvard University Press, 1962).

Bungard, A. (2009). Un compromiso apasionado. María Zambrano: una intelectual al servicio del pueblo (1928-1939). Madrid, España: Editorial Trotta.

Cámara, M. (2001). Vocación de Casandra. New York, USA: Editorial Peter Lang.

Derrida, J. (1989). “La palabra soplada”. En Derrida, J., La escritura y la diferencia (pp. 233-270). Barcelona, España, Editorial Anthropos.

Johnson, R. (2003). Gender and Nation in the Spanish Modernist Novel. Nafhville, USA: Vanderbilt University Press.

Laurenzi, E. (1995). María Zambrano, nacer por sí misma. Madrid, España: Editorial Horas y Horas.

Moreno Sanz, J. (1993). La razón en la sombra: antología crítica. Madrid, España: Editorial Siruela.

Moreno Sanz, J., Ed. (1998). Los intelectuales en el drama de España y escritos de la guerra civil, $1^{\text {ra }}$ ed. Madrid, España: Editorial Trotta.

Ortega, J. F. (1982). María Zambrano o la metafísica recuperada. Málaga, España: Universidad de Málaga y Ayuntamiento de Vélez Málaga. 
Ortega, J. F. (2007). María Zambrano. La aventura de ser mujer. Málaga, España: Editorial Veramar.

Riffaterre, M. (1978). Semiotics of Poetry. Bloomington, USA: Indiana University Press.

Soto, H. (1996). España: 1936: antología de la solidaridad chilena. Santiago de Chile, Chile: Lom Ediciones.

Soto, P. (2005). "La irrupción de lo femenino en el pensamiento de María Zambrano", en Actas del Congreso Internacional del Centenario de María Zambrano. Vélez Málaga, España: Fundación María Zambrano, pp. 444-451.

Tomashevsky, B. (1965). “Tematics”. En Ed. Lee T. Lemon, L. T. and Reiss, Marion. J. Reiss (Eds.), Russian Formalist Criticism: Four Essays (pp. 61-95). Lincoln: Nebraska University Press.

Unruh, V. (2006). Performing Women and Modern Literary Culture in Latin America. Austin, USA:, University of Texas Press.

Valender, J. (2010). "María Zambrano y su visión de América Latina. Lectura de cuatro ensayos". Nueva Revista de Filología Hispánica 58(2), 619-643.

Valente, J. A. (1982). "Del conocimiento pasivo o saber de quietud". En Ortega, J. F., María Zambrano o la metafísica recuperada (pp. 103-108). Málaga, España: Universidad de Málaga y Ayuntamiento de Vélez Málaga.

Zambrano, M. (1934). "Hacia un saber sobre el alma”. Revista de Occidente, XLVI(138), 261-276.

Zambrano, M. (1937a). "A los poetas chilenos de Madre España". En Huidobro, V. et al., Madre España: homenaje de los poetas chilenos (pp. 38-39). Santiago de Chile, Chile. Editorial Panorama.

Zambrano, M. (1937b). "La reforma del entendimiento". Atenea, 140, 115-124.

Zambrano, M. (1937c). "Españoles fuera de España”. En Zambrano, M. (1986), Senderos (pp. 170-174). Barcelona, España: Editorial Anthropos (Hora de España VII, Valencia - Barcelona, 59-62).

Zambrano, M. (1937d). "La guerra de Antonio Machado". Hora de España XII, 68-74.

Zambrano, M. (1977). Claros del bosque. Barcelona, España: Seix Barral.

Zambrano, M. (1986). Senderos. Barcelona, España: Editorial Anthropos. 